\title{
Evaluation of Economical and Ecological Aspects of Denim Garments Dyeing with Fluorescent Dye
}

\author{
Muhammad Abdur Rashid ${ }^{1}$, Md. Delwar Hossain ${ }^{1}$, Muhammad Mufidul Islam², Md. Nakib-Ul-Hasan ${ }^{2}$ \\ ${ }^{1}$ Department of Textile Engineering, Dhaka University of Engineering \& Technology (DUET), Gazipur, Bangladesh \\ ${ }^{2}$ Department of Textile Engineering, Northern University Bangladesh, Dhaka, Bangladesh \\ Email: rashid@duet.ac.bd, del_wartex@yahoo.com
}

Received October 9, 2013; revised November 9, 2013; accepted November 17, 2013

Copyright (C) 2013 Muhammad Abdur Rashid et al. This is an open access article distributed under the Creative Commons Attribution License, which permits unrestricted use, distribution, and reproduction in any medium, provided the original work is properly cited. In accordance of the Creative Commons Attribution License all Copyrights (C) 2013 are reserved for SCIRP and the owner of the intellectual property Muhammad Abdur Rashid et al. All Copyright (C) 2013 are guarded by law and by SCIRP as a guardian.

\begin{abstract}
In this study the existing process ( 3 steps) and proposed process ( 2 steps) were evaluated during dyeing of denim fabric with fluorescent dye. It compared the effectiveness of these two processes of fluorescent dyeing in the textile industry. Here at first the grey denim fabric was pretreated by scouring and bleaching. Then the fabric was dyed in existing process i.e. through catanizing, dyeing and binding at $10 \%$ and $15 \%$ shades. Again the pretreated fabric was dyed in proposed process i.e. through catanizing and (dyeing and binding) with same shades. Then the properties of two types of dyed fabric were compared. This study provides a set of experimental results, discussion and comparison between the two processes. The results show that the proposed process has less power and time consumption and more water savings compared to existing process. So the evaluation reflected that the proposed process was much more effective than existing process of denim dyeing with fluorescent dye.
\end{abstract}

Keywords: Fluorescent Dyestuff; Denim Fabric; Fastness Properties

\section{Introduction}

Bangladesh is in $4^{\text {th }}$ position in textile in world survey [1]. In our country mainly woven and knit fabrics are used in garments sector. Dyed fabric or white fabrics are used in garments sector. Their almost all dye used in Bangladesh. Nowadays the application of fluorescent dye for both woven and knitted fabrics are increasing day by day for its brilliance color appearance although the fastness properties are not so good.

There are several very early reports of the usual fluorescent brilliance of certain dyes when applied to natural textile fiber, the most pronounced effect being obtained on silk. The greenish-yellow fluorescent and it's orange to red halogenated derivatives (eosin) were among the dyes but there practical use was limited by inadequate fastness properties. The brilliant bluish red rhodamines were found to exhibit rather better fastness properties on textiles and they are the most important classes of fluorescent dyes for a wide range of application. Research aimed at producing new fluorescent dyes for using in the coloration of textile, coating and plastics has continued in recent years with the objectives of extending the avail- able product shade range enhancing fluorescent intensity and improving other useful application properties such as light fastness and thermal stability. In addition several new applications have emerged which specifically exploit light emission properties of fluorescent dyes [2]. Techniques involving the use of specific fluorescent dyes are of immense importance in biological and medical research providing a useful Lolo in the search for new biologically active compounds and the potential for the development of new diagnostic methods [3]. It is difficult to arrive at a precise definition of what constitutes a fluorescent dye. Florescent dye is a chemical that contains a lot of property. Especially it is renowned for its special photo physical property. A lot of people are trying to implement this dye on textile field. TENCEL ${ }^{\circledR}$ (Lyocell) and other man-made cellulosic fibers using a fluorescent dye molecular probe [4]. Only TENCEL shows a significant difference between dried and never-dried fibers and it is mainly due to the structure of TENCEL. But if it is done on the other method it expects that it may bring an outstanding result. The use of hemi cyanine dyes to bring the effect that is similar to fluorescent effect [5]. 
The results showed that those dyed acrylic fabrics using hemi-cyanine dyes had obvious fluorescent effect in the spectra range $550-750 \mathrm{~nm}$. But the effect that is brought by florescent is not same here. So it is possible to make an experiment by using fluorescent dye in the process reduction method that brings an effect in the spectra range $550-750 \mathrm{~nm}$. An improvement in fastness to sublimation; washing and perspiration (both acidic and alkaline) were observed but there was no general improvement in light fastness compared with the parent compounds [6]. The fluorescent azo disperse dyes were applied on polyester fiber and they finally probe that it enhances various fastness property [7]. Another experiment was carried out on wool, silk and nylon with fluorescent acid azo dyes and obtained photo physical properties increased but no fastness property was noticed [8]. The maximum fluorescent reflectance would reach under acid medium dyeing $(\mathrm{pH}=5)$, adding fluorescent brightener can obviously raise the reflectance [9]. At the same time other properties remain constant. So it would be very interesting if it is possible to increase other properties with the reflectance property. The experimental results show that more complete chromatogram of fluorescent acrylic yarn can be obtained with suitable proportion of mixed dyestuff in combination dyeing [10]. The purpose of this research is to reduce the process steps of fluorescent dyeing of denim garments without changing fabric properties including ecological and economical benefit.

\section{Materials and Methods}

\subsection{Materials}

The investigation has been carried out with $100 \%$ cotton $3 / 1$ twill denim fabric. The yarn count was $7 \mathrm{~s} / 1$ carded yarn, the fabric weight per unit area was $372 \mathrm{~g} / \mathrm{m}^{2}$, EPI 68 and PPI 38 respectively. The fabric was scoured and bleached by caustic soda and hydrogen per oxide in a single bath stage with the standard recipe [11]. Then the denim fabrics were dyed with fluorescent dye in various shade percentage.

\subsection{Methods}

\subsubsection{Pretreatment Process}

The denim cotton fabric has been subjected to scouring and bleaching process for removal natural impurities such as wax, pectin, fat, oil, pigment etc from cotton fibers [12]. Here scouring and bleaching was carried out by using suitable recipe (Table 1) with maintaining proper time and temperature. After pretreatment the fabric was washed off two times i.e. hot wash and cold wash and then dried. Then the pretreated denim fabric was used for the experimental process. The same pretreated sample has been used for existing process and
Table 1. Recipe of scouring and bleaching process.

\begin{tabular}{cc}
\hline Process parameter & Amount \\
\hline Wetting agent & $1 \mathrm{gm} / 1$ \\
Sequestering agent & $1 \mathrm{gm} / 1$ \\
Detergent & $1 \mathrm{gm} / 1$ \\
Caustic soda & $4 \mathrm{gm} / 1$ \\
Hydrogen per oxide & $5 \mathrm{gm} / 1$ \\
Stabilizer & $2 \mathrm{gm} / 1$ \\
Temperature & $95^{\circ} \mathrm{C}$ \\
Time & $1 \mathrm{hour}$ \\
\hline
\end{tabular}

also for the proposed process.

\subsubsection{Dyeing}

1) Existing Process

The pretreated fabric was treated with $5 \mathrm{gm} / 1$ catanizer (Cat MDN-96, Texodyes Company, Bangladesh) at $50^{\circ} \mathrm{C}$ temperature for 20 minutes in $\mathrm{pH} 8.5$. Then the dye bath was prepared by $10 \%$ and $15 \%$ of fluorescent red, fluorescent yellow and fluorescent blue separately and combined in the liquor ratio 1:10. After catanizing, the fabric was performed cold wash. Then the sample was added to each dye bath and dyeing was commenced 10 minutes at room temperature then raised temperature to $60^{\circ} \mathrm{C}$ for 20 minutes. The dyed sample was washed with cold water and treated with $3 \mathrm{gm} / \mathrm{l}$ binder for 5 minutes and finally cold wash at room temperature and then dried in oven.

2) Proposed Process

The pretreated fabric was treated with $5 \mathrm{gm} / 1$ catanizer (Cat MDN-96, Texodyes Company, Bangladesh) at $50^{\circ} \mathrm{C}$ temperature for 20 minutes in $\mathrm{pH} 8.5$. Then the dye bath was prepared by $10 \%$ and $15 \%$ of fluorescent red, fluorescent yellow and fluorescent blue separately and combined in the liquor ratio 1:10. After catanizing, the fabric was performed cold wash. Then the sample was added to each dye bath and dyeing was commenced 20 minutes at temperature $60^{\circ} \mathrm{C}$ with $3 \mathrm{gm} / 1$ binder. Finally the dyed fabric was performed cold wash at room temperature and then dried in oven.

\subsubsection{Fabric Parameter Test}

Treated all fluorescent dyed denim fabric were conditioned in $65 \% \mathrm{RH}$ and at $20^{\circ} \mathrm{C}$ for 24 hours before testing according to ASTM D1776 [13]. Shade matching was performed by data color machine. Dye yield capacity $(\mathrm{k} / \mathrm{s})$ of the fabric was tested according to kubel-kumung theory by data color machine. Fabric brightness test was also performed by data color machine. The values for color fastness were rated with a grey scale for color change and color staining according to AATCC test method 61 [14]. SEM was studied using a scanning electron microscope (model-S 3400N, Hitachi, Japan). 


\section{Result and Discussion}

\subsection{Color Difference Measurement}

Calculation of small color Differences for acceptability CMC (Color Measurement Committee) values for different shade percentages are estimated from the dyed fabrics by existing process \& proposed process. The results are shown (Table 2).

CIE (Commission Internationale de I'Eclairage) color coordinates include color qualities in terms of $\mathrm{L}^{*}$ (lightness and darkness), a* (redness and greenness), $b^{*}$ (yellowness and blueness), $\mathrm{c}^{*}$ (chroma) and $\mathrm{H}$ (hue) of the fabrics are shown in Table 2. The $\Delta \mathrm{E}$ values of differently dyed fabrics. $\Delta \mathrm{E}$ value contains the information of color depth, shade, and the hue of a sample. $\Delta \mathrm{E}$ value is calculated by using the CIE $L^{*}$, $a^{*}$, and $b^{*}$ values with the equation $\Delta \mathrm{E}=\left(\Delta \mathrm{L}^{* 2}+\Delta \mathrm{a}^{*^{2}}+\Delta \mathrm{b}^{* 2}\right)^{1 / 2}$ where $\Delta \mathrm{L}^{*}$, $\Delta \mathrm{a}^{*}$, and $\Delta \mathrm{b}^{*}$ values were the difference between $\mathrm{L}^{*}, \mathrm{a}^{*}$, and $b^{*}$ values of a pair of color standard and sample. The larger the $\Delta \mathrm{E}$ value, the greater will be the color difference between this pair of color standard and sample. In this case the color difference was expected because the CMC value was less than 1.0 after dyeing existing and proposed process. The experiment was carried out under light source of D65 at $10^{\circ}$ and the result shows the satisfactory result remarks as "pass".

\subsection{Color Fastness to Rubbing}

In this project work color fastness to rubbing assessments are done for both fabrics dyed by existing process and proposed process. This test was designed to determine the degree of color which may be transferred from the surface of a colored fabric to a specify test cloth for rubbing which could be dry and wet. The dyed fabric was subjected to test fastness to rubbing. This test result showed in Table 3, where good rubbing fastness for $10 \%$ and $15 \%$ shade of proposed process compared to existing process dyed of denim fabrics. Because the time for migration of dye was more in proposed process. The experiment was carried out according to the ISO105X12 method. Table 3 shows the test results.

\subsection{Color Fastness to Wash}

In this experiment color fastness to wash assessments are used for dyed fabric both existing and proposed process. The resistance of a material to change in any of its color characteristics, when subjected to washing is called color fastness to washing. In the test, change in color of the textile and also staining of color on the adjacent fabric were assessed.

Color fastness was usually assessed separately with respect to fading and staining. This test shows (Figure 1) good to excellent wash fastness for color changed and staining of the proposed process compared to the existing process. Because the reaction of proposed process has combined than the existing process.

\subsection{Power Consumption}

The power requirement for proposed process is less than existing process. Table 4 shows the comparison

Figure 2 indicates that the power requirement in proposed process is less than in existing process which is about $25 \%$.The evaluation was carried out for $100 \mathrm{~kg}$ garments.

\subsection{Time Consumption}

The time requirement for proposed process is less than existing process. The existing process takes place about 1 hour and 15 minutes for completion whereas the proposed process will not take more than 55 minutes for completion the whole process of dyeing. Thus for every

Table 2. CMC values of existing process \& proposed process dyed fabric.

\begin{tabular}{cccccccc}
\hline Shade \% & $\Delta \mathrm{E}$ & $\Delta \mathrm{L}^{*}$ & $\Delta \mathrm{a}^{*}$ & $\Delta \mathrm{b}^{*}$ & $\Delta \mathrm{c}^{*}$ & $\Delta \mathrm{H}$ & $\begin{array}{c}\mathrm{CMC} \\
\text { Value }\end{array}$ \\
\hline $\mathbf{1 0} \%$ & 1.98 & 0.89 & $\begin{array}{c}1.59 \\
(-)\end{array}$ & $\begin{array}{c}0.77 \\
(-)\end{array}$ & $\begin{array}{c}0.34 \\
(-)\end{array}$ & 1.74 & 0.88 \\
$\mathbf{1 5 \%}$ & 1.97 & 1.00 & $\begin{array}{c}1.70 \\
(-)\end{array}$ & 0.11 & 0.52 & 1.62 & 0.86 \\
\hline
\end{tabular}

Table 3. Comparison of color fastness to rubbing of existing and proposed process.

\begin{tabular}{cccccc}
\hline \multirow{2}{*}{ Process } & Shade & \multicolumn{2}{c}{ Test Result } & \multicolumn{2}{c}{ Sample view } \\
\cline { 3 - 5 } & & Dry & Wet & Dry & Wet \\
\hline $\begin{array}{c}\text { Existing } \\
\text { Process }\end{array}$ & & $3 / 4$ & $2 / 3$ & & \\
& $15 \%$ & 3 & 2 & \\
& & & & \\
Proposed & & & & \\
Process & $10 \%$ & $4 / 5$ & $2 / 3$ & \\
\hline
\end{tabular}

Table 4. Power consumption in existing and proposed processes.

\begin{tabular}{ccc}
\hline Process & $\begin{array}{c}\text { Required Power in Unit } \\
\text { (Kilo Watt/Hour) }\end{array}$ & $\begin{array}{c}\text { Power saved in } \\
\text { \% }\end{array}$ \\
\hline Existing Process & 20 & 25 \\
Proposed Process & 15 & \\
\hline
\end{tabular}




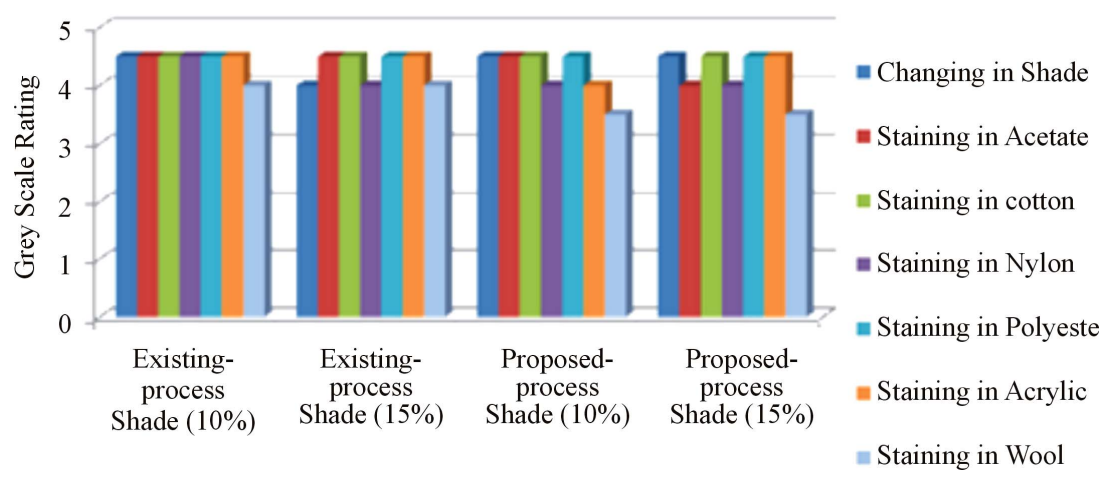

Figure 1. Graphical representations of color fastness to wash for existing and proposed process.

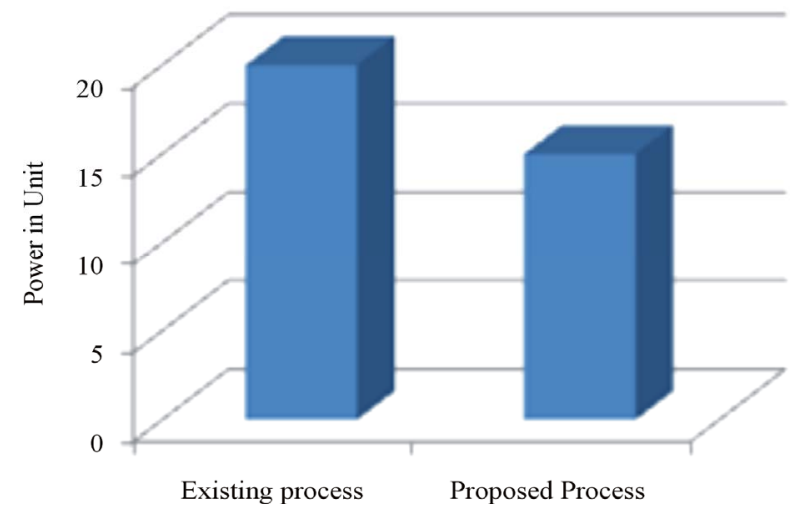

Figure 2. Power requirements in existing and proposed processes.

batch dyeing the proposed process will save 20 minutes. It will also reduce the production cost of the whole process and adding the economical benefit. In terms of percentage the time saving will be $26.67 \%$ which is shown in Table 5. The whole process was evaluated for $100 \mathrm{~kg}$ garments.

\subsection{Water Consumption}

The water requirement for proposed process is less than existing process. Table 6 shows the comparison

In proposed process two baths are used whereas in existing process a minimum of three baths are used. This leads to a total one bath saving. Considering material liquor ratio of 1:10; the total amount of water that will be saved is about 20 liters for every $\mathrm{kg}$ garments for dyeing. For above result $100 \mathrm{~kg}$ garments were undertaken for considering the total result.

\subsection{Surface View on Micro Macro Projector}

The Microscopic view of grey fabric, dyed fabric (proposed process, exsiting process) are given below (see Figures 5-7):

The Figures (Figures 5-7) show that there is a little bit difference among surface views of grey fabric, fabric

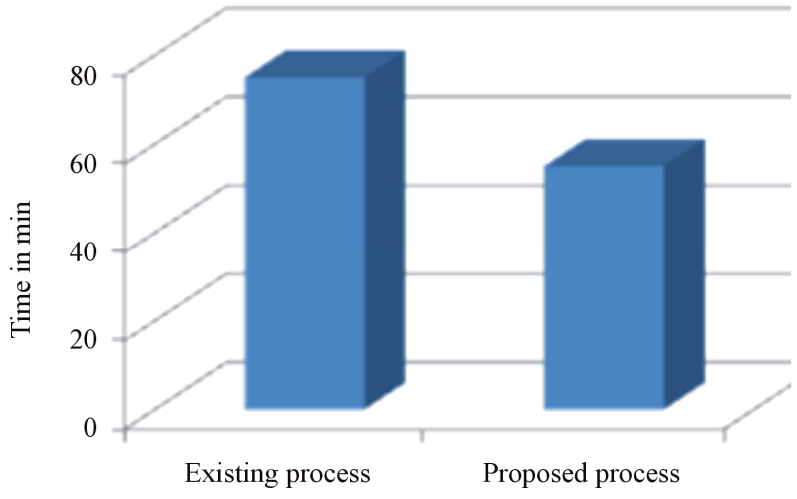

Figure 3. Time requirement for existing and proposed process.

Table 5. Time comparison in existing and proposed processes.

\begin{tabular}{ccc}
\hline Process & Required Time (min) & Time saved in \% \\
\hline Existing Process & 75 & 26.67 \\
Proposed Process & 55 & \\
\hline
\end{tabular}

Table 6. Water requirements for existing and proposed processes.

\begin{tabular}{ccc}
\hline Process & $\begin{array}{c}\text { Required water } \\
\text { in Liter }\end{array}$ & Water saved in \% \\
\hline Existing Process & 5981 & 33.43 \\
Proposed Process & 3981 & \\
\hline
\end{tabular}

dyed by existing process \& proposed process. Finally it is observed that the surface views of fabric dyed by proposed process at different shade $\%$ are comparatively smoother than any other.

\section{Conclusion}

The results show that the properties of the dyed fabric with existing and proposed process remain similar. It was observed that the value of CMC less than 1 i.e. 0.88 and 0.86 of $10 \%$ and $15 \%$ shaded respectively of existing and proposed process. But the fastness properties of the pro- 


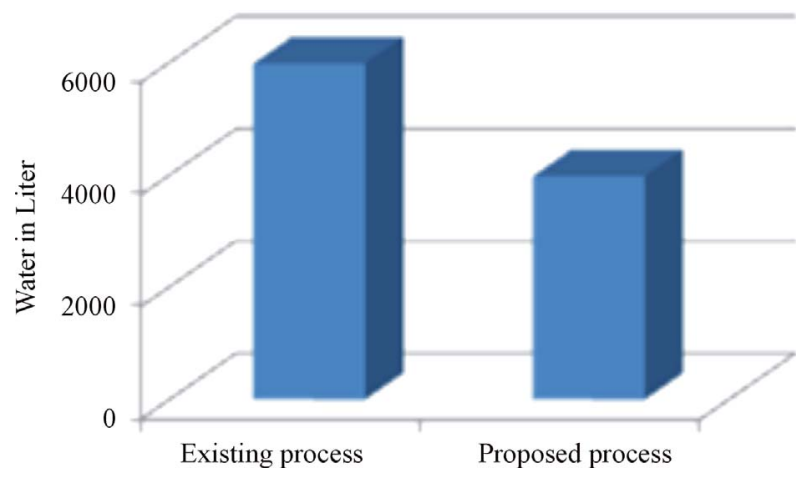

Figure 4. Water requirements in existing and proposed processes.

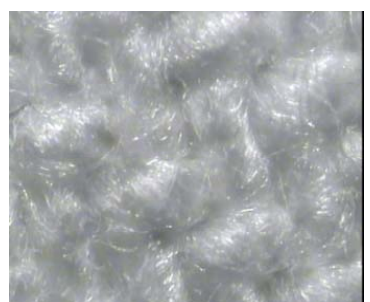

Back view (Grey)

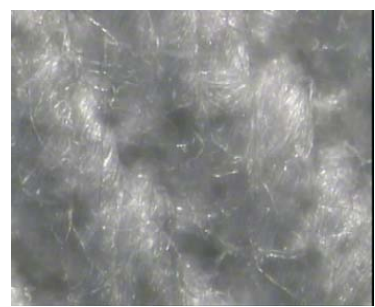

Front view (Grey)
Figure 5. Microscopic view of grey fabric.

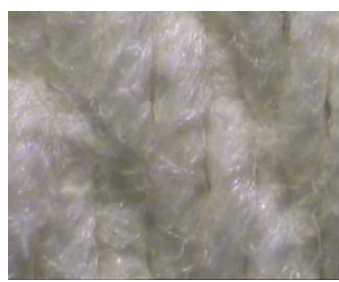

Front view at $10 \%$ shade

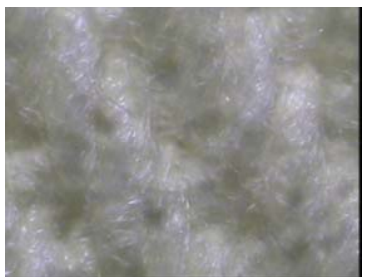

Front view at $15 \%$ shade

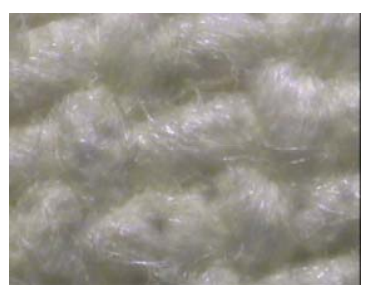

Back view at $10 \%$ shade



Back view at $15 \%$ shade
Figure 6. Microscopic view of dyed fabric by existing process.

posed process were better than the existing process. Another important activity of the research work was to analyze the impact of the proposed process an economical and ecological aspect which shows that proposed process give better result compared to the existing process. It is shown that the proposed process saved about $25 \%$ of power consumption, $26.67 \%$ of time consumption and $33.43 \%$ of water consumption compared to the existing process. The study clearly indicates the economical savings of production cost also scope for a sustainable process development to support the eco-friendly textile proc-

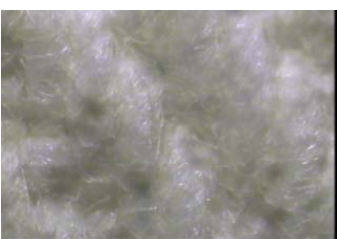

Front view at $10 \%$ shade

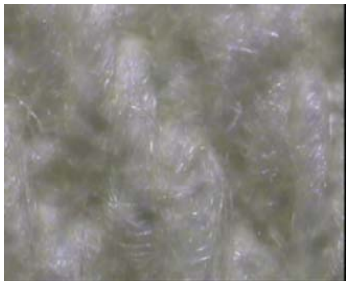

Front view at $15 \%$ shade

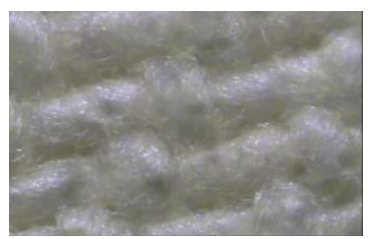

Back view at $10 \%$ shade

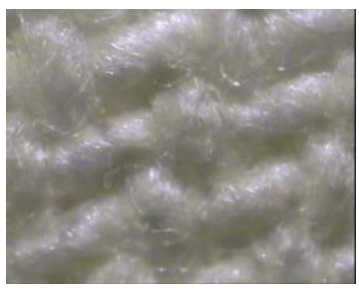

Back view at $15 \%$ shade
Figure 7. Microscopic view of dyed fabric by proposed process.

essing by releasing high pressure on energy and utility consumption.

\section{REFERENCES}

[1] Dorpon Textiles Limited, Source: EPB compiled by RDTI. 2011.

www.dorpangroup.com/dtextiles/default.aspx

[2] T. Gülümser, E. Karagöz and E. P. A Kumbasar, "A Research About Dyeing Of Cotton Fibers With Fluorescent Dyestuffs And Developing Light Fastness," Tekstil Ve Konfeksiyon, 2008.

[3] G. Cosa1, K.-S. Focsaneanu, J. R. N. McLean, J. P. McNamee and J. C. Scaiano, "Photophysical Properties of Fluorescent DNA-Dyes Bound to Single- and Double-stranded DNA in Aqueous Buffered Solution," Photochemistry and Photobiology, Vol. 73, No. 6, 2001, pp. 585-599.

http://dx.doi.org/10.1562/0031-8655(2001)073<0585:PP OFDD $>2.0 . \mathrm{CO} ; 2$

[4] M. Abu-Rous, K. Varga, T. Bechtold and K. C. Schuster, "A New Method to Visualize and Characterize the Pore Structure of TENCEL $\AA$ (Lyocell) and Other Man-Made Cellulosic Fibres Using a Fluorescent Dye Molecular Probe," Article First Published Online: 23 JUL 2007.

[5] C. X. Qin, R.-C. Tang, B. Chen, D. W. Chen, X. M. Wang and Q. Chen, "Study on the Dyeing Properties of Hemicyanine Dyes. I. Acrylic Fabrics, Fibers and Polymers," Fibers and Polymers, Vol. 11, No. 2, 2010, p. 8.

[6] R. M. Christie, K. M. Morgan and M. S. Islam, "Molecular Design and Synthesis of N-Arylsulfonated Coumarin Fluorescent Dyes and Their Application to Textiles," School of Textiles and Design, Scottish Borders Campus, Heriot-Watt University, Galashiels TD1 3HF, Scotland, 2008.

[7] M. A. Satam, R. K. Raut and N. Sekar, "Fluorescent Azo Disperse Dyes from 3-(1, 3-Benzothiazol-2-yl) Naphthalen-2-Ol and Comparison with 2-Naphthol Analogs," Dyes and Pigments, Vol. 96, No. 1, 2013, pp. 92-103. 
http://dx.doi.org/10.1016/j.dyepig.2012.07.019

[8] M. A. Satam, R. K. Raut and N. Sekar, "Fluorescent Acid Azo Dyes from 3-(1,3-Benzothiazol-2-yl)Naphthalen-2$\mathrm{O} 1$ and Comparison with 2-Naphthol Analogs," Dyes and Pigments, Vol. 97, No. 1, 2013, pp. 32-42. http://dx.doi.org/10.1016/j.dyepig.2012.11.007

[9] W.-F. Yang and L.-J. Yang, "Polyamide Dyeing with Fluorescent Dye," Tianjin Polytechnic University, Tianjin, 2004.

[10] L. Wang and L. Hu, "Combination Dyeing and One-Bath Process of Whitening and Dyeing of Fluorescent Acrylic Yarns”, Journal of Textile Research, Key Laboratory of Advanced Textile Materials and Manufacturing Technology, Ministry of Education, Zhejiang Sci-Tech University, Hangzhou, 2008.
[11] H. Panda, "Proposed Technology of Textiles Dyes \& Pigments," National Institute of Industrial Research, Delhi, India, pp. 247-253.

[12] E. R. Trotman, "Dyeing and Chemical Technology of Textile Fibers," 4th Edition, Charles Griffin \& Company Ltd, London, 1970, pp. 190-197.

[13] ASTM D 1776, "Standard Practice for Conditioning Textiles for Testing," American Society for Testing and Materials, Annual Book of ASTM Standards, Vol. 7, No. 1, ASTM International, West Conshohocken, PA, USA, 2008.

[14] AATCC Test Method 61, "Colorfastness to Laundering, Home and Commercial: Accelerated," American Association of Tex Research Triangle Park, N.C., USA, 2010. 